\title{
REVIEW ON APPLICATION OF GASOLINE DIRECT INJECTION AND ENGINE DOWNSIZING IN TWO WHEELERS AND TO MEET BHARAT STAGE SIX EMISSION NORMS
}

\author{
Onkar Mohapatra ${ }^{1}$, Prithv Singh Pradhan ${ }^{2}$ \\ ${ }^{I}$ Pre-final year (B.Tech), Department of Mechanical Engineering College of Engineering and Technology, \\ Bhubaneswar-751003 \\ onkarmohapatra1995@gmail.com \\ ${ }^{2}$ Pre-final year (B.Tech), Department of Mechanical Engineering College of Engineering and Technology, \\ Bhubaneswar-751003 \\ prithvi274@gmail.com
}

\begin{abstract}
The 2 wheelers in the market now-a-days are causing high levels of emission due to scavenging losses, uneconomical operation and high maintenance cost due to fresh charge losses. Furthermore there is no scope for lean operation. So the report aims to incorporate a Gasoline Direct Injection in a 2 wheeler in order to increase efficiency and improve emission conditions of the vehicle in order to achieve Bharat Stage VI norms.

The basic objective of the report is to:

1. Incorporate Gasoline Direct Injection in a 2-wheeler vehicle with required changes to be made in the storage and distribution facility i.e. - the fuel pump.

2. Basic downsizing of the vehicle to reduce cost that will be added in order to control emission.

3. Achieve Bharat Stage VI norms of emission, by controlling particulate matter emission, which is to be incorporated by 2020.
\end{abstract}

Keywords: Bharat Stage-VI, EMS, Fuel Stratification, MPFI, Piezoelectric Injector, Turbo charger, Oil belt drive,

Dual mass flywheel, CATIA V5 R19

\section{INTRODUCTION}

The Gasoline Direct Injection system is a type of fuel injection system where gasoline is highly pressurized and directly injected into the combustion chamber of each cylinder rather than the conventional multipoint fuel injection that injects fuel into intake tract. Due to the use of Gasoline Direct Injection ultra-lean burn of fuel can be achieved, thus resulting in better fuel efficiency. Although GDI has been incorporated in many 4 wheeler vehicles, but incorporation in a 2 wheeler vehicle is an altogether new idea.

The GDI engine has a number of advantages like increased fuel efficiency and high power output. The emission rates are also controlled, especially the $\mathrm{NO}_{\mathrm{x}}$ and hydrocarbon part of the emission. In a GDI engine, there is no air throttle plate which reduces throttling losses. Thus it increases fuel efficiency by reducing pumping losses. Engine speed is controlled by the engine control unit/engine management system(EMS), which regulates fuel injection function and ignition timing, instead of having a throttle plate that restricts the incoming air supply. The EMS carries out operations in the engine using 3 modes:

1. Ultra-lean burn or stratified charge mode which is used for low load operations without any acceleration.

2. Stoichiometric mode used for moderate load conditions creating a homogenous fuel-air mixture.
3. Full power mode used in heavy load condition and rapid acceleration which uses a richer mixture.

Although the GDI engine has a number of advantages, it sure has some primary disadvantages like:

1. The design of a suitable of fuel pumps for high pressure gasoline direct injection which needs to be uniform in all the cylinders.

2. Although the emission of $\mathrm{NO}_{\mathrm{x}}$ and hydrocarbon has been greatly reduced in the GDI engine system, but the amount of particulate emission coming from the engine is greatly increased in the GDI engine.

3. Due to the use of GDI engine, the vehicle becomes bulky and big. So basic downsizing needs to be done in the vehicle to reduce the size as well as decrease the cost of the vehicle which might increase due to incorporation of GDI engine as well as to control emission.

4. Using a highly precise Engine Management System to control fuel injection and ignition timing in the engine and helping in establishing a better performance of the engine.

In the report, we aim to achieve a solution to the above mentioned problems and come up with some new ideas to improve the efficiency and performance of the vehicle keeping in mind the Bharat Stage VI norms for emission control. 


\section{GASOLINE DIRECT INJECTION FOR TWO-WHEELERS}

The Gasoline Direct Injection (GDI) or in other words Fuel Stratified Injection (FSI) is a modern technique used in four stroke gasoline engines. Unlike the conventional multi-point fuel injection (MPFI) technique, GDI allows a highly pressurized Gasoline directly into the combustion chamber. The major benefits of incorporating GDI engines in twowheelers are greater fuel economy and increasing power output simultaneously. Though GDI has great advantages over modern MPFI as well as traditional carburetor system, it is difficult to implement in two wheelers due to the limitation in the design of the combustion chamber and the fuel pump. Thus the main objective of our report is to propose a design of the combustion chamber, piston and the fuel pump that can incorporate increased fuel economy, better cold start performance and better drive co mfort.
To ensure higher thermal efficiency and minimum heat conduction out to the cylinder walls, a region with minimu m surface-volume ratio must be used. A hemispherical shaped chamber provides least surface-volu me ratio. For even flame front the hemispherical chamber is designed with sparkplug at the center. Now the concern is about the flow of air motion. According to Reference [3], Tumble flow generates proper mixing of air and fuel, and for high flame propagation rate. Also a well-defined (single vortex) tumbling flow structure is more stable. Thus it is important to create tumble inside the cylinder. The piston head shape also affects mixing tendency on air and fuel, hence pent roof type piston is used to increase turbulence. This type of pistons contains W-shaped curve which assists tumble motion of air.

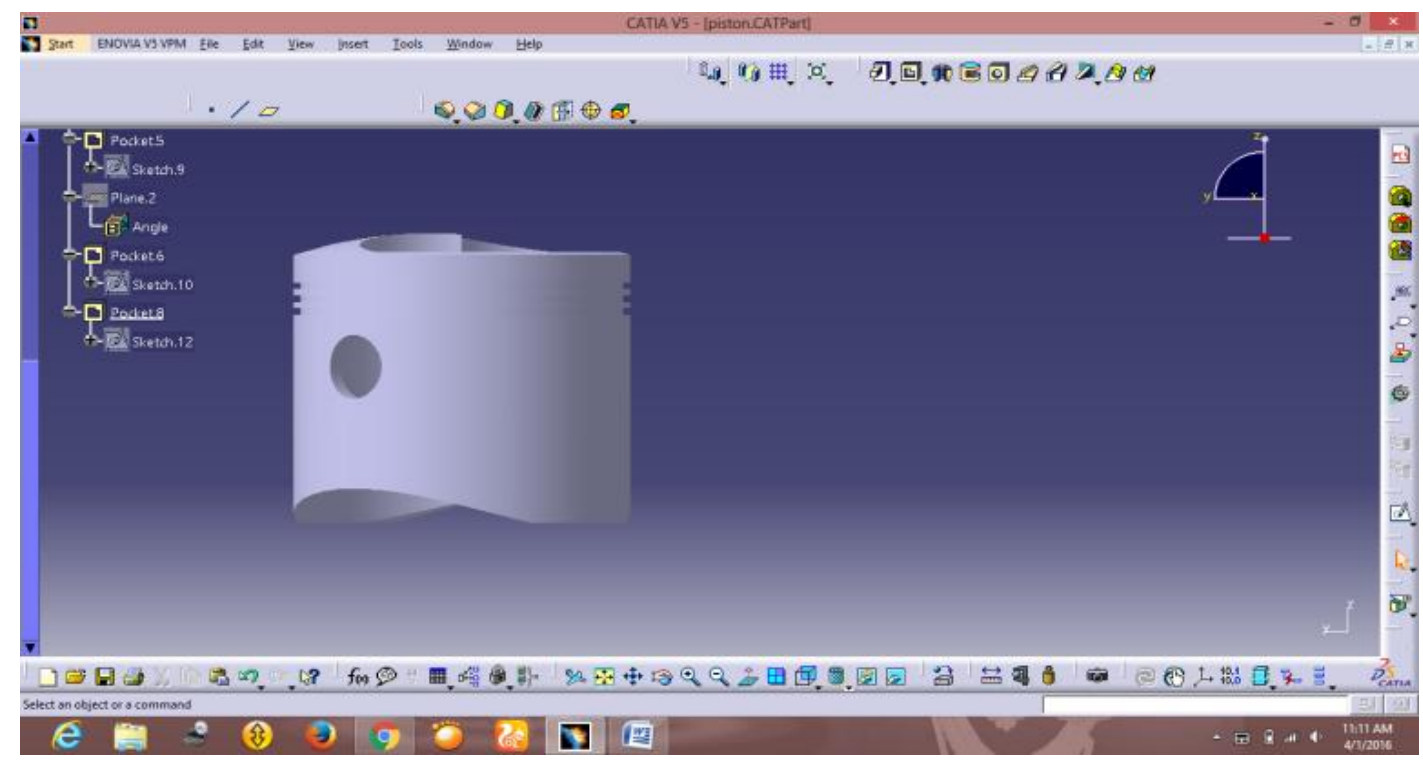

Fig- 1: Front of the pent-roof piston head

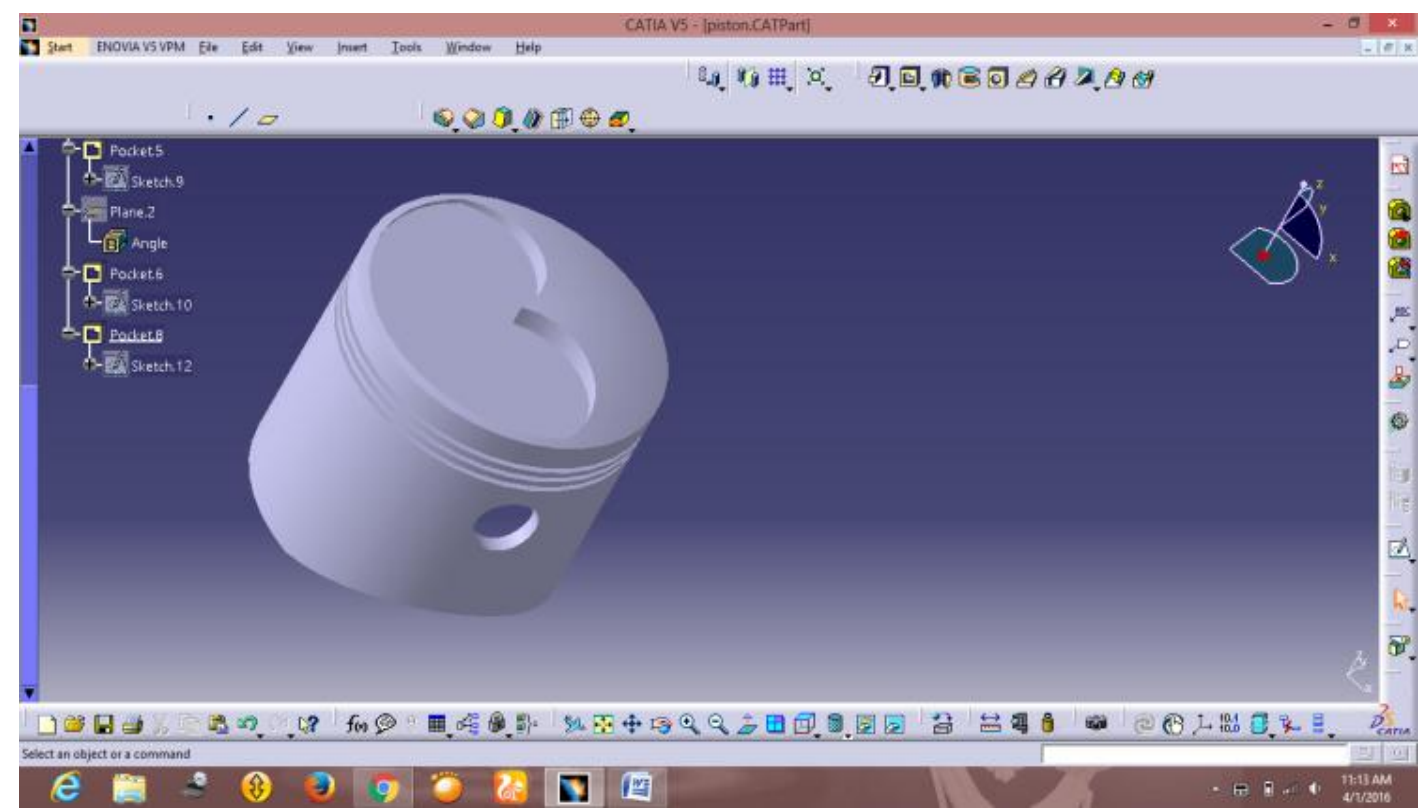

Fig- 2: Iso metric view of the pent-roof piston 
The fuel injection system in GDI engine plays a very important role. For implementation of GDI in two wheelers it is important to have a high pressure fuel pump. It is also solely responsible late injection for stratified charge combustion at part load and early injection for homogeneous charge combustion during full load. For stratified charge combustion a well atomized, repeatable fuel pattern is required to achieve rapid combustion. Thus the key technology for such control of fuel can be done by EMS containing microcontrollers. The lambda sensor provides information about the richness in air-fuel mixture. The power-train control modules (PCM) use this to constantly re-adjust the air-fuel ratio. The coolant sensor measures the engine temperature and the PCM uses this information to regulate a wide variety of ignition, fuel and emission control functions. Once the engine reaches a certain temperature, the PCM starts using the signal from the lambda sensor to vary the fuel mixture. The crankshaft position sensor serves in monitoring engine $\mathrm{rpm}$ and helps the computer determining the relative position of the crankshaft so the PCM can control spark timing and fuel delivery in the proper sequence.

Now coming on to the high pressure fuel injector, our idea is to incorporate piezo injectors instead of using traditional solenoid injectors in two wheelers. This injector is smaller in size as well as increases the engine efficiency and can be operated at high engine speeds. Piezo in jectors works on the principle of piezo electric technology to open and close fuel injectors at extreme precision level. The in jectors consist of several hundreds of piezoelectric crystals for its operation. When electricity is passed through these crystals, due to expansion of the crystals, the injector opens up and gets closed as soon as electricity is stopped. Another reason for which piezo injectors should by chosen, is the ability to inject fuel in cylinder several times in one stroke. Hence no fuel gets wasted and thus increases fuel economy.

\section{EMISSION CONTROL}

For achieving Bharat Stage VI norms the following values of emission needs to be considered:

(The following values are considered for a gasoline passenger car engine)

1. CO emission values remain same for BS IV and BS VI i.e. $-1 \mathrm{~g} / \mathrm{km}$.

2. Similarly there is no change in hydrocarbon emission values for both BS IV and BS VI i.e. - $0.1 \mathrm{~g} / \mathrm{km}$.

3. The $\mathrm{NO}_{\mathrm{x}}$ emission values needs to decrease from 0.8 $\mathrm{g} / \mathrm{km}$ for BS IV to $0.6 \mathrm{~g} / \mathrm{km}$ for BS VI.

4. However the particulate matter emission values needs to decrease to $0.005 \mathrm{~g} / \mathrm{km}$ for BS VI which was earlier not a big concern in BS IV.

Thus, it relates that the control of emission of $\mathrm{CO}$ and $\mathrm{HC}$ will not be a bigger concern as it remains almost the same and the required engine does not produce much of those emissions. However the major concern would lie on the decrease of $\mathrm{NO}_{\mathrm{x}}$ and the particulate matter emission. Although the $\mathrm{NO}_{\mathrm{x}}$ decrease is rather a very insignificant matter but the maximum amount of particulate matter that needs to be controlled is rather a very big issue as the GDI engine would emit large amount of particulate matter and along with which there is a control over the emission values in BS VI which was not a major concern in BS IV.

\section{CONTROLLING THE PARTICULATE MATTER EMISSION}

The major problem is the GDI soot which oxidizes 2-5 times faster than diesel engine and the GDI ash which is produced due to higher engine speeds.

A very efficient method for reducing the particulate emission is to pass the exhaust gas into a ceramic honeycomb containing multiple cells that are defined by porous walls, and then discharging the exhaust gas through the exhaust manifold. The porous walls of the honeycomb like structures will trap the particulate emissions. The porous walls are of thickness $150-750 \mu \mathrm{m}$ and an effective permeability of $0.8 \times 10^{-12} \mathrm{~m}^{2}$. The ceramic honeycomb must contain at least 45,000 to 230,000 cells per square meter.

The filters, commonly known as "honeycombs", have axial cells that extend the length of the filter from an inlet end to an outlet end. The cells are defined and separated by porous walls. The cells are plugged in a pattern that forces exhaust entering the filter to pass through a cell wall before it escapes from the filter. Particulate matter is captured by the cell walls.

Although the particulate emission would be reduced due to the use of honeycomb structures in the exhaust manifold, but the GDI filters do not accumulate much soot cake (which is rather a more efficient way of trapping particulate matter than clean filters), so the GDI filters would need to perform at rather high efficiency in order to trap the same amount of particulate matter. A thick soot formation in GDI filtration would rather be detrimental due to increase in backpressure. So the filter should work efficiently at a very low pressure drop.

\section{ENGINE DOWNSIZING}

When somebody thinks of the term downsizing a vague idea forms in our mind about how the size of the engines can be decreased without compromising the power and torque produced. This is exactly what we have tried to achieve in our engine.

Motorbike engines should be small because of the obvious reason that the available spaces in bikes are limited. Besides after extensive study it has been observed that downsizing actually aids the possibility of Gasoline Direct Injection.

Again smaller engines can help to achieve the upcoming BHARAT STAGE VI emission norms as they produce lesser emissions compared to heavier and larger engines. The compactness and cost effectiveness of these downsized small engines also adds another dimension to their usefulness. 
Various parameters can be considered to achieve downsizing

1. Tu rbocharging

2. Using Integrated Exhaust Manifold

3. Using Split Cooling

4. Using a Dual Mass Flywheel

5. Belt dipped in oil drive rather than chain drive

The engine exhaust can be reused in Turbocharged engines to increase the amount of air sucked in compared to the normal aspirated engines. A massive flow of induced air ensures better combustion and higher power production capability. Turbocharged engines have better performance than the traditional supercharging but they can be weak in response. Therefore it is imperative to use a twin charger engine in those models where cost is not a factor.

What if the exhaust manifold was itself part of the engine .It would then save a lot of space as well as the cost of production. These two factors encourage integrating the exhaust manifolds into the engine itself.

The heat generated is concentrated in specific areas of the engine Also the heat requirement is different in separate regions. Therefore to obtain optimum performance it is necessary to provide cooling to these hot spots. This calls for using a split cooling system. The split cooling efficiently cools down these areas and decreases the requirement of cooling each and every part of the engine. It basically consists of a water jacket and a distributer. Water is the coolant used because of the fact that is has high heat carrying capacity as well as easily available .A split cooling system gives a unique advantage to an engine as it allows optimum temperatures at different points and maximizes overall effect of cooling system to the engine performance.

Rather than traditional flywheels we can use a dual mass flywheel which can ensure a continuous supply of energy as well as reduces vibrations. This reduction in vibration saves loss of useful energy and enables in downsizing. Although the dual mass flywheels are difficult to machine and are a bit costly but nonetheless their excellent damping capability cannot be neglected.

Since downsizing is all about reducing weight and size, it also comes down to transmission where the conventional chain drive adds to the weight of the engine. An efficient replacement for the chain drive is a belt dipped in oil drive system. Numerous advantages of this belt drive include noiseless operation, less cost, reduced weight and free from possibility of corrosion.

\section{CONCLUSION}

It is expected that these methods can be successfully implemented in two wheelers. The piezo-electric injector implemented enhances the fuel economy and also reduces the overall weight.These methods also adhere to the BHARAT STAGE VI norms that are to be implemented in 2016 in India. Gasoline direct injection along with downsizing is an excellent future prospective and can be adopted in motor bikes.

\section{REFERENCE}

[1]. Zhao Fuquan, Harrington David, "Automotive Gasoline Direct Injection”, 2002.

[2]. Sharma R.P, Mathur M.L, "Internal Combustion Engines", 2010, DhanpatRai Publications.

[3]. Subarao P, "Design of Intake Systems for better incylinder turbulent flow", Retrieved from http://web.iitd.ac.in/ p mvs/courses/mel713/mel713 29.ppt.

[4]. Mani Kausik, Jain Vineet, “Development Of Mechanical Gasoline Direct Injection Engines For 4 Stroke Two Wheeler", ManipalUniersity, India.

[5]. Majkowski .Stephen, "Filtration of gasoline direct injection engine exhausts with honeycomb filters", US Patent WO2014085325 A1, June 5, 2014.

\section{BIOGRAPHY}

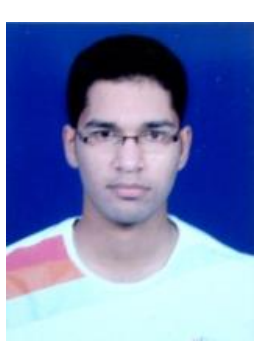

OnkarMohapatrais presently pursuing Bachelor in Technology degree in Mechanical Engineering from College of Engineering and Technology, Bhubaneswar, Odisha, India. $\mathrm{He}$ is a member of the American Society of Automobile Engineers (ASME), India and presently a Student Council Representative at ASME CET Bhubaneswar Chapter. He is also the innovation team head of the team "The Gutsy Gladiators" that won 7th rank in innovation event of ASME HPVC INDIA 2016 held in Vellore Institute of Technology. He has completed a design course in CATIA software from Central Tool Room and Training Centre, Bhubaneswar. He can be contacted through the email address: onkarmohapatra1995@g mail.com.

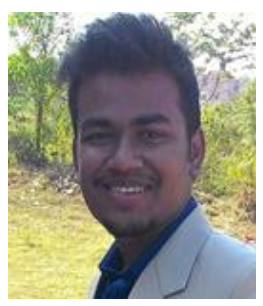

Prithv Singh Pradhan is currently pursuing his Bachelor in Technology degree in Mechanical Engineering from College of Eng ineering and Technology, Bhubaneswar, Odisha, India. He currently holds the position of treasurer in American Society of Mechanical Engineers (ASME) CET Bhubaneswar Chapter. He was also part of the innovation team of the team "The Gutsy Gladiators "that won $7^{\text {th }}$ rank in innovation event of ASME HPVC INDIA 2016 held in Vellore Institute of Technology. His research interest areas include I.C Engine development, thermal heat transfer, and fluid currents. He has done his internship in ADI, Bangalore. He is also well versed in designing software like CATIA and ANSYS. He can be contacted both through his email address prithvi274@gmail.com and phone number 918598869806. 